\title{
Attenuation of oxidative stress, inflammation and apoptosis by ethanolic and aqueous extracts of Crocus sativus L. stigma after chronic constriction injury of rats
}

\author{
BAHAREH AMIN ${ }^{1}$, KHALIL ABNOUS $^{2}$, VAHIDEH MOTAMEDSHARIATY ${ }^{3}$ \\ and HOSSEIN HOSSEINZADEH ${ }^{4}$ \\ ${ }^{1}$ Department of Pharmacology and Physiology, Cellular and Molecular Research Center, School of Medicine, \\ Sabzevar University of Medical Sciences, 5714445994 Sabzevar, Iran \\ ${ }^{2}$ Department of Biotechnology, School of Pharmacy, Mashhad University of Medical Sciences, 1365-91775 Mashhad, Iran. \\ ${ }^{3}$ Pharmaceutical Research Center, Mashhad University of Medical Sciences, 1365-91775 Mashhad, Iran \\ ${ }^{4}$ Pharmaceutical Research Center, Department of Pharmacodynamics and Toxicology, \\ School of Pharmacy, Mashhad University of Medical Sciences, 1365-91775 Mashhad, Iran
}

Manuscript received on February 12, 2014; accepted for publication on June 30, 2014

\begin{abstract}
In our previous study, the ethanolic and aqueous extracts of Crocus sativus elicited antinociceptive effects in the chronic constriction injury (CCI) model of neuropathic pain. In this study, we explored anti-inflammatory, anti-oxidant and anti-apoptotic effects of such extracts in CCI animals. A total of 72 animals were divided as vehicle-treated CCI rats, sham group, CCI animals treated with the effective dose of aqueous and ethanolic extracts (200 mg/kg, i.p.). The lumbar spinal cord levels of proinflammatory cytokines including tumor necrosis factor $\alpha(\mathrm{TNF}-\alpha)$, interleukin- $1 \beta$ (IL-1 $\beta$ ) and interleukin 6 (IL-6), were evaluated at days 3 and 7 after $\mathrm{CCI}(\mathrm{n}=3$, for each group). The apoptotic protein changes were evaluated at days 3 and 7 by western blotting. Oxidative stress markers including malondialdehyde (MDA) and glutathione reduced (GSH), were measured on day 7 after CCI. Inflammatory cytokines levels increased in $\mathrm{CCI}$ animals on days 3 and 7, which were suppressed by both extracts. The ratio of Bax/ Bcl2 was elevated on day 3 but not on day 7, in CCI animals as compared to sham operated animals and decreased following treatment with both extracts at this time. Both extracts attenuated MDA and increased GSH levels in CCI animals. It may be concluded that saffron alleviates neuropathic pain, at least in part, through attenuation of proinflammatory cytokines, antioxidant activity and apoptotic pathways.
\end{abstract}

Key words: Crocus sativus, chronic constriction injury, inflammatory cytokines, oxidative stress, apoptosis.

\section{INTRODUCTION}

For years, medicinal plants have been identified as an important source of new chemical substances with potential therapeutic effects. Saffron, the dried stigmas of Crocus sativus L., (Iridaceae family), has been used for coloring and flavoring in food preparations (Abdullaev 1993). Traditionally, this

Correspondence to: Hossein Hosseinzadeh

E-mail: hosseinzadehh@mums.ac.ir plant has been used as a color and seasoning in food. Moreover, in folklore medicine, saffron has been used in the treatment of numerous illnesses including cough, asthma, menstruation problems, insomnia, pain relief, colic, chronic uterine hemorrhage, cardiovascular disorders and tumors (Abdullaev and Espinosa-Aguirre 2004, Hosseinzadeh and Nassiri-Asl 2013). Scientific studies have verified many traditional uses of such expensive spice. Saffron 
extracts and its active constituents, safranal and crocin, have shown anti-cancer (Abe and Saito 2000, Rastgoo et al. 2013), anti-oxidant (Hosseinzadeh et al. 2009), anti-convulsant (Hosseinzadeh et al. 2008), anti-depressant (Hosseinzadeh et al. 2003), anti-anxiety (Hosseinzadeh and Noraei 2009) and memory improvement properties (Hosseinzadeh and Ziaei 2006), in addition to antinociceptive and anti-inflammatory properties in different kinds of in vitro and in vivo studies (Hosseinzadeh and Younesi 2002, Hosseinzadeh and Shariaty 2007). Pain initiated or caused by a primary lesion or dysfunction in the nervous system is defined as being a neuropathic pain and triggers a cascade of events in the central or peripheral nervous system, including excitotoxicity, oxidative stress, inflammatory process and apoptotic like cell death mechanisms (Maione et al. 2002). In our previous work, antiallodynic and antihyperalgesic effects of ethanolic and aqueous extracts of saffron were shown in rats that underwent chronic constriction injury (CCI) of the sciatic nerve (Amin and Hosseinzadeh 2012). However, the exact mechanisms which underlie the antinociceptive effect of this plant is still unknown. Anti-inflammatory and antioxidant effects of saffron and its main constituents have been demonstrated in many investigations. The serum levels of prostaglandin F2 $\alpha$, a marker of lipid peroxidation was significantly decreased by crocin and safranal following subacute intoxication by an organophosphorus, diazinone. In addition, crocin, reduced serum tumor necrosis factor $\alpha(\mathrm{TNF}-\alpha)$ level (Hariri et al. 2010). LPSstimulated release of TNF- $\alpha$, interleukin- $1 \beta$ (IL$1 \beta$ ), and intracellular reactive oxygen species (ROS) were attenuated by crocin and crocetin in rat brain microglial cells (Nam et al. 2010). Safranal attenuated oxidative damage induced by an ischemia reperfusion injury (IRI) model in hippocampus of rats (Hosseinzadeh and Sadeghnia 2005). Radical scavenging activity of plant extracts and their bioactive constituents, crocin and safranal, was shown in DPPH (1,1-diphenyl-2-dipicrylhydrazyl) radical scavenging test (Assimopoulou et al. 2005) as well as microsomal lipid peroxidation induced by $\mathrm{Fe} 2+$ /ascorbat (Hosseinzadeh et al. 2009). In this study crocin exhibited more antioxidant effect than safranal moiety. Saffron extract and safranal showed cardioprotective effect by decreasing lactate dehydrogenase (LDH) and creatine kinase (CK-MB) and myocardial lipid peroxidation in isoproterenol-induced myocardial infarction in Wistar rats (Mehdizadeh et al. 2013). Crocin also prevented cytotoxicity induced by a potent neurotoxin, acrylamide as well as diazinone-induced hepatotoxicity in Wistar rats via decreasing Bax/Bcl2 ratio, as well as ROS generation inhibition (Mehri et al. 2012, Lari et al. in press). Consequently, this investigation was aimed at evaluating neuroprotective effects of both ethanolic and aqueous extracts of $C$. sativus by assessing time course of changes in the proinflammatory factors (TNF- $\alpha$, IL- $1 \beta$ and IL-6) and apoptotic changes with measuring $\mathrm{Bax} / \mathrm{Bcl} 2$ ratio in the spinal cord lumbar enlargement of 3 and 7 days-CCI animals. At the end of the experiment, the alteration of oxidative damage markers including glutathione reduced (GSH), the major sulfhydryl (-SH) antioxidant (Cooper and Kristal 1997) and malondialdehyde (MDA), the last product of lipid peroxidation (Cheesman 1993) were also evaluated in the spinal cord lumbar section of animals.

\section{MATERIALS AND METHODS}

ANIMALS

All experiments were performed on adult male Wistar rats, weighing 220-260 g, randomly obtained from the animal room of the Faculty of Pharmacy, Mashhad University of Medical Sciences, Iran. Animals were kept in a $12 \mathrm{~h}$ light-dark cycle environment. Tap water and standard food pellets were available ad libitum. All procedures were approved by Mashhad University of Medical Sciences (Grant No: 89998) and followed the Internationally Accepted Principles for Laboratory Animal Use and Care (Zimmermann 1983). 


\section{MATERIALS}

Stigma of C. sativus L. was purchased from Novin Saffron Co. (Mashhad, Iran) collected from Ghaen, Khorasan province, Northeast of Iran and analyzed in accordance to ISO/TS 67321-2. Aqueous and ethanolic extracts were extracted from saffron's stigma in our laboratory. The saffron extracts were dissolved in normal saline $(0.9 \%)$ immediately before injection and administered intraperitoneally once a day, from the day of surgery, for 7 consecutive days. Ketamine and xylazine were purchased from Alfasan Co. (Woerden, Holland).

\section{PREPARATION OF EXTRACTS}

Ethanolic extract: $10 \mathrm{~g}$ of saffron powder was mixed with $25 \mathrm{ml}$ ethanol $80 \%$ at $0{ }^{\circ} \mathrm{C}$ and shaked by vortex for $2 \mathrm{~min}$. After centrifugation at $4000 \mathrm{~g}$ for $10 \mathrm{~min}$, the supernatant was separated. Extraction by ethanol from sediment was repeated 6 other times. As a result, the total volume of solvent consumption for $10 \mathrm{~g}$ of saffron stigmas was $200 \mathrm{~mL}$ $(8 \times 25 \mathrm{~mL})$. The resulting solution was dried in a rotary evaporator system in darkness at $35^{\circ} \mathrm{C}$.

Aqueous extract: Saffron powder was mixed with distilled water $(1 / 50 \mathrm{~W} / \mathrm{V})$ and left on a shaking incubator at $8{ }^{\circ} \mathrm{C}$ for $48 \mathrm{~h}$. The solution was centrifuged at $4000 \mathrm{~g}$ for $10 \mathrm{~min}$. The resulting supernatant was retained and sediment was suspended in the half amount of mentioned distilled water and placed on the shaking incubator for another $24 \mathrm{~h}$. The centrifugation was repeated again and the yielded supernatant was separated and stored at $-20{ }^{\circ} \mathrm{C}$ in a freezer. Sublimation of solvent was performed by freeze drying.

\section{SURGERY OF SCIATIC NERVE}

Mononeuropathy was induced by performing chronic constriction injury model on the left sciatic nerve of animals as previously described (Bennett and Xie 1988). At first, rats were anaesthetized under a cocktail of ketamine and xylazine (64/1.6 $\mathrm{mg} / \mathrm{kg}$, i.p.). After the incision of the skin, the sciatic nerve was exposed and four ligatures of 4-0 gauge chromic catgut were tied loosely with an interval of $1 \mathrm{~mm}$, until a slight twitching was observed in the expected hind paw. Finally, muscle and skin were separately sutured with 4-0 silk catgut and animals were placed in a warm condition until recovery.

\section{STUDY PROTOCOL}

Based on our previous study, CCI led to the significant development of mechanical allodynia $(4.3 \pm 0.6 \mathrm{~g}$ vs $53 \pm 6.7 \mathrm{~g})$ and cold allodynia (73.3 $\pm 8.4 \%$ vs $8 \pm 4.9 \%$ ) on day 3 in comparison to sham group, as revealed by von Frey hairs and acetone drop, respectively. Pain behaviors increased progressively during the study on days 5 and 7. In that study, the mechanical allodynia and cold allodynia were significantly attenuated by the aqueous ( $16 \pm 2.4 \mathrm{~g}$ and $32.5 \pm 3.4 \%$ respectively) and ethanolic extracts of saffron $(32.8 \pm 8 / 4 \mathrm{~g}$ and $17.5 \pm 5.7 \%$, respectively) at the dose of $200 \mathrm{mg} / \mathrm{kg}$ on day 3 (Amin and Hosseinzadeh 2012). In the present study, to examine the time course of changes in proinflammatory cytokines and apoptosis-related proteins in the spinal cord of CCI rats, three animals from each group were harvested on postoperative day 3 , or 7 after the behavioral tests. In order to measure spinal cord MDA or GSH, three animals from each group were sacrificed on postoperative day 7 .

Hence, 72 animals were randomly assigned into the following groups:

Groups 1, 2: The animals were subjected to CCI surgery, treated with normal saline (NS) at a dose of $1 \mathrm{ml} / \mathrm{kg}$ and killed on day 3 for evaluation of proinflammatory cytokines $(\mathrm{n}=3)$ and apoptotic factors $(n=3)$.

Groups 3, 4: Sham group: The animals underwent a similar surgery with the exception that the sciatic nerves were not ligated and they were treated with the normal saline and killed on day 3 for evaluation of proinflammatory cytokines $(n=3)$ and apoptotic factors $(n=3)$. Groups 5, 6: 
CCI animals were treated with ethanolic extract of saffron $(200 \mathrm{mg} / \mathrm{kg}$, administered at a dose of $1 \mathrm{ml} / \mathrm{kg}$ ) for seven days and killed on day 3 for evaluation of proinflammatory cytokines $(n=3)$ and apoptotic factors $(n=3)$. Groups 7, 8: CCI animals were treated with aqueous extracts of saffron (200 $\mathrm{mg} / \mathrm{kg}$, administered at a dose of $1 \mathrm{ml} / \mathrm{kg}$ ) for seven days and killed on day 3 for evaluation of proinflammatory cytokines $(\mathrm{n}=3)$ and apoptotic factors ( $n=3)$. Groups 9-12: The CCI animals were treated with NS, and killed on day 7 for evaluation of proinflammatory cytokines $(n=3)$, apoptotic factors $(n=3), \operatorname{MDA}(n=3)$ and GSH $(n=3)$.

Groups 13-16: Sham operated animals were killed on day 7 for evaluation of proinflammatory cytokines $(n=3)$, apoptotic factors $(n=3)$, MDA $(n=3)$ and GSH $(n=3)$. Groups 17-20: CCI animals were treated with ethanolic extract of saffron $(200 \mathrm{mg} / \mathrm{kg})$ for seven days and killed on day 7 for evaluation of proinflammatory cytokines $(n=3)$, apoptotic factors $(n=3)$, MDA $(n=3)$ and GSH $(n=3)$. Groups 21-24: CCI animals were treated with aqueous extracts of saffron $(200 \mathrm{mg} / \mathrm{kg})$ for seven days and killed on day 7 for evaluation of proinflammatory cytokines $(n=3)$, apoptotic factors $(n=3)$, MDA $(n=3)$ and GSH $(n=3)$.

For the protein extraction, the lumbar spinal cord was rapidly ejected from the vertebral column using a saline-filled syringe, as quickly as possible and then separated on dry ice. The choice of examining the L4 and L5 segments was based on the consideration that these lumbar segments are the major contributors to the sciatic nerve (Bennett and Xie 1988).

\section{TISSUE PREPARATION}

Tissue samples were placed in the individual tubes and quickly frozen in liquid nitrogen and then stored at $-80{ }^{\circ} \mathrm{C}$ until usage. Determination of protein content was performed by Bradford assay kit (BioRad) and adjusted (Bradford 1976).
DETECTION OF TNF-A, IL-1B AND IL-6, IN THE LUMBAR SPINAL CORD BY ELISA

At the time of experiment, samples were immediately homogenized in the extraction buffer $(20 \mathrm{mM}$ Tris (pH 7.4, Sigma-Aldrich), containing $150 \mathrm{mM}$ $\mathrm{NaCl}$ (Sigma-Aldrich), $1 \mathrm{mM}$ EDTA (SigmaAldrich), 2 mM 2-N-morpholinoethanesulfonic acid (2 ME) (Sigma-Aldrich) and one complete protease inhibitor tablet (Roche, Mannheim, Germany) (Reece et al. 2004). Cytokine levels in the lumbar spinal cord of rats were measured according to the manufacturer's instructions, specific for TNF- $\alpha$, IL$1 \beta$ and IL-6 (Koma Biotech, Korea). The content of each sample was obtained according to the standard curve at $450 \mathrm{~nm}$.

\section{WESTERN BLOTTING}

Western blot analysis of Bax and Bcl2 proteins, in the lumbar spinal cord

Samples of tissues were homogenized in the lysis buffer containing $50 \mathrm{mM}$ Tris- $\mathrm{HCl}$ (pH: 7.4), $2 \mathrm{mM}$ EDTA, $2 \mathrm{mM}$ EGTA, $10 \mathrm{mM} \mathrm{NaF}$, $1 \mathrm{mM}$ sodium orthovanadate (Na3VO4), $10 \mathrm{mM}$ $\beta$-glycerophosphate, $0.2 \% \mathrm{~W} / \mathrm{V}$ sodium deoxycholate, $1 \mathrm{mM}$ phenylmethylsulfonyl fluoride (PMSF), and complete protease inhibitor cocktail (Roche, Mannheim, Germany). Homogenate was sonicated on ice with three 10 -sec bursts at high intensity with a 10 -sec cooling period between each burst and then centrifuged at 10,000g for $10 \mathrm{~min}$ at $4{ }^{\circ} \mathrm{C}$. After determining protein content by Bradford protein assay kit (BioRad) and adjusting the protein concentration, each sample was mixed 1:1 v:v with 2x SDS blue buffer. After boiling for $5 \mathrm{~min}$, samples were aliquoted and stored at $-80{ }^{\circ} \mathrm{C}$ in a freezer.

At the time of experiment, samples containing $50 \mu \mathrm{g}$ of protein were loaded on a $12 \%$ sodium dodecyl polyacrylamide gel and electrotrensferred to polyvinylidene fluoride (PVDF) membranes. After transfer, nonspecific binding sites were blocked with low-fat milk in TBS containing 20 
$\mathrm{mM}$ Tris- $\mathrm{HCl} \mathrm{pH} 7.6,137 \mathrm{mM} \mathrm{NaCl}$ (TBS-T) at $4{ }^{\circ} \mathrm{C}$ overnight. The probed membranes were then incubated with primary antibodies including: rabbit polyclonal anti-B-cell lymphoma 2 (Bc12), rabbit polyclonal anti-Bcl-2-associated $\mathrm{X}$ protein (Bax) and rabbit polyclonal anti- $\beta$ actin antibodies (Cell Signaling, 1: 1000) for 1-2 hours at room temperature. After three washes with TBST, blots were incubated with rabbit horseradish peroxidase-conjugate anti-rabbit IgG (Cell Signaling, 1:2000) as a secondary antibody for 1 hour. Enhanced chemiluminescence (Pierce) and Alliance $4.7 \mathrm{Gel}$ doc (UK) were used to visualize the peroxidase-coated bands. Protein bands were densitometrically quantified using UVtec software (UK). To compare the differences between control and treatment groups, the relative optical density of each specific band to sham group was normalized against the density of the corresponding internal loading band, $\beta$-actin as a control protein.

\section{Measurement of MDA LeVELs In The Lumbar}

SPINAL CORD

Estimation of lipid peroxidation was performed by measuring the Malondialdehyde (MDA) using the thiobarbituric acid assay (Uchiyama and Mihara 1978). At the time of experiment, each sample was weighed and a homogenate (10\%) was prepared in $1.15 \%$ potassium chloride solution. At first, $3 \mathrm{ml}$ of phosphoric acid (1\%) and $1 \mathrm{ml}$ of TBA $(0.6 \%)$ were added to $0.5 \mathrm{ml}$ of homogenate and the mixture was heated for $45 \mathrm{~min}$ in a boiling water bath. After cooling, $4 \mathrm{ml}$ of $\mathrm{n}$-butanol was added to the mixture and vortex-mixed for $1 \mathrm{~min}$ followed by centrifugation at $3000 \mathrm{rpm}$ for 15 minutes. The organic layer was transferred to a fresh tube and its absorbance was read at $532 \mathrm{~nm}$. A calibration curve was constructed using MDA (Sigma-Aldrich) as standard. Protein content was determined by Bradford protein assay kit (BioRad) and the results were expressed as nmol/mg protein.
MEASURMent OF GSH LeVELS IN THE LuMBAR SPINAL CoRD

Total SH groups belonging to GSH were measured using DTNB (2, 2'- dinitro-5, 5'-dithiodibenzoic acid) as the reagent. A $10 \%$ tissue homogenate in buffer phosphate 7.4 was mixed with an equal volume of $10 \%$ trichloro acetic acid (TCA) and vortexed. The contents were then centrifuged at $5000 \mathrm{rpm}$ for $10 \mathrm{~min}$. Each $3.5 \mathrm{ml}$ reaction mixture contained 0.5 of supernatant, $2.5 \mathrm{ml} 0.1 \mathrm{M}$ phosphate buffer (pH 8.4) and $0.5 \mathrm{ml}$ DTNB. The absorbance was measured at $412 \mathrm{~nm}$ using a spectrophotometer within $15 \mathrm{~min}$. GSH was determined from a standard curve constructed using commercially available standard GSH (Sigma-Aldrich). Protein content was determined by Bradford protein assay kit (BioRad). Levels of GSH were expressed as $\mathrm{nmol} / \mathrm{mg}$ protein (Moron et al. 1979).

\section{Statistical Methods}

Data were expressed as means \pm SEM for 3 rats in each group and statistically analyzed by one-way ANOVA followed by Tukey's post hoc tests, using SPSS version 13. A P value of $<0.05$ was considered to be significant.

\section{RESULTS}

THE EFFECTS OF Crocus sativus EXTRACTS ON THE PROINFLAMMATORY CYTOKINES

CCI resulted in a significant elevation of spinal cord TNF- $\alpha$ especially on day $3(\mathrm{P}<0.001)$ as well as on day 7 after $\mathrm{CCI}(\mathrm{P}<0.01)$ in comparison to the sham group (Fig. 1A). IL- $1 \beta$ also significantly increased on days 3 and 7 after CCI in comparison to the sham group ( $\mathrm{P}<0.01$, Fig. 1B). IL-6, however, with a delay (no difference on day 3 ) showed a significant increase only on the 7 th day post-CCI in comparison to the sham operated rats $(\mathrm{P}<0.001$, Fig. $1 \mathrm{C})$. As shown in fig. $1 \mathrm{~A}$, the contents of TNF- $\alpha$ was significantly lower on days $3(\mathrm{P}<0.05)$ and $7(\mathrm{P}<0.05)$ in animals treated with intraperitoneal administration of 200 
$\mathrm{mg} / \mathrm{kg}$ of both extracts. The contents of IL-1 $\beta$ was significantly lower on days $3(\mathrm{P}<0.05)$ and $7(\mathrm{P}$ $<0.05)$ in animals treated with intraperitoneal administration of ethanolic extract (Fig. 1B). Cotreatment with aqueous extract $(200 \mathrm{mg} / \mathrm{kg})$ for seven days attenuated the levels of IL- $1 \beta$ on day $3(\mathrm{P}<0.01)$ and day $7(\mathrm{P}<0.05)$ after CCI (Fig. 1B). Seven days treatment with extracts attenuated spinal cord IL-6 in comparison to saline treated CCI animals $(\mathrm{P}<0.05$, Fig. $1 \mathrm{C})$.
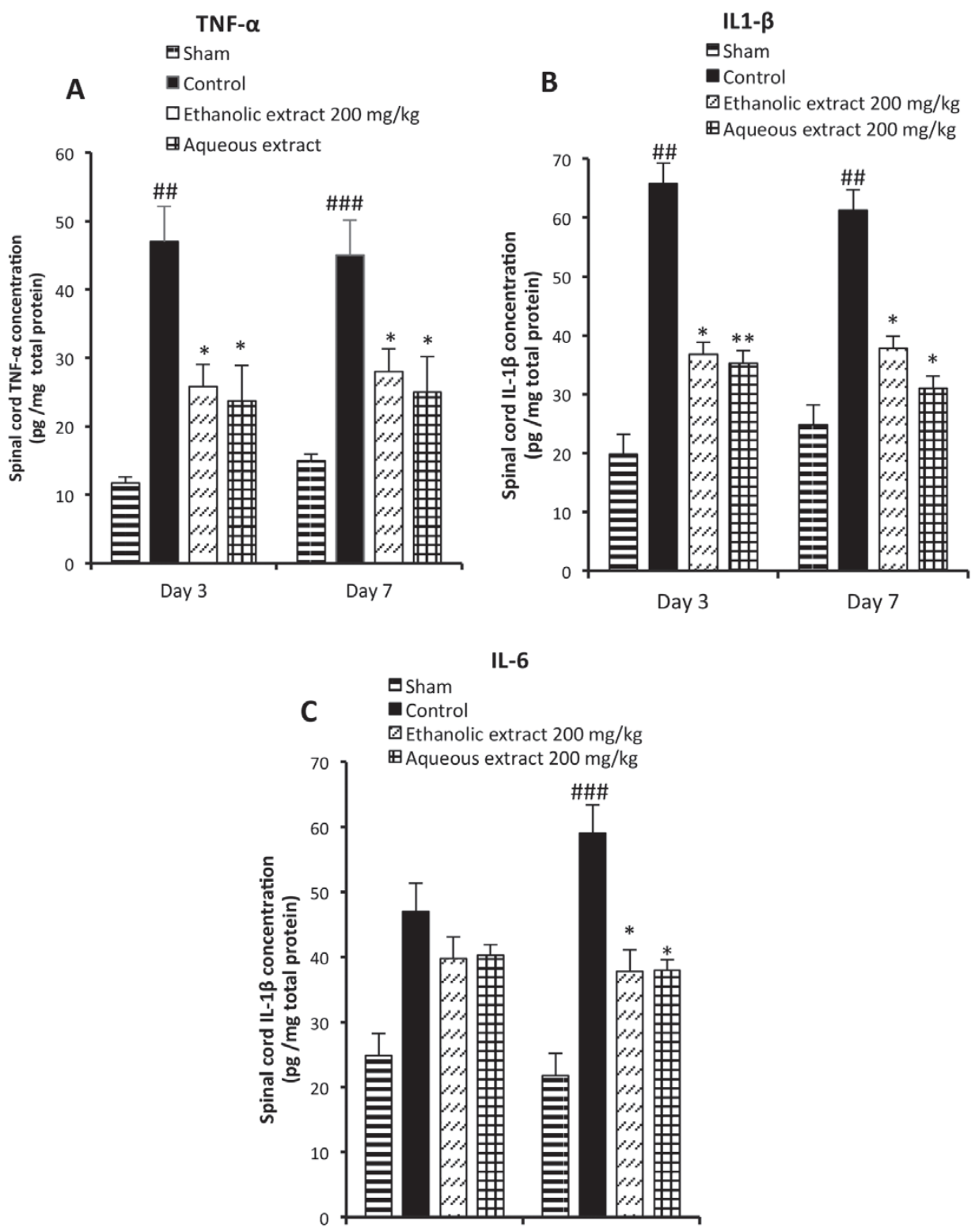

Figure 1 - The effect of aqueous extract $(200 \mathrm{mg} / \mathrm{kg})$ and ethanolic extract $(200 \mathrm{mg} / \mathrm{kg})$ of Crocus sativus on the lumbar spinal cord levels of TNF- $\alpha$ (A), IL-1 $\beta$ (B) and IL-6 (C), on 3 days and 7 days sciatic nerve CCI rats. Administration of extracts was started from the day of surgery and continued for seven consecutive days. CCI significantly induced elevated levels of TNF- $\alpha$ and IL-1 $\beta$ on days 3 and 7. IL-6 was significantly elevated on day 7 after CCI. Data are presented as mean \pm SEM for $n=3$ / group. One-way ANOVA followed by Tukey's post-hoc test was used for multiple comparisons. $* \mathrm{P}<0.05$ and $* * \mathrm{P}<0.01$ indicate a statistically significant difference when compared to CCI normal saline-treated rats. \#\# $\mathrm{P}<0.01$, \#\# $\mathrm{P}<0.001$ : Difference between CCI-NS and sham-operated rats. 
THE EFFECTS of Crocus sativus EXTRACTS ON THE MDA AND GSH LEVELS

MDA and GSH were measured one week after surgery. As shown in Table I, a significantly higher spinal cord MDA level was observed in the CCI group treated by normal saline relative to sham animals $(\mathrm{P}<0.01)$. CCI caused a significant decrease in the amount of GSH of spinal cord of animals, in comparison to the sham group $(\mathrm{P}<0.05)$ (Table I). MDA levels were significantly attenuated following the 7 days treatment of ethanolic $(\mathrm{P}<$ $0.01)$ and aqueous extracts of saffron $(\mathrm{P}<0.05)$. As indicated in Table I, lumbar spinal cord contents of GSH was restored by co-treatment of aqueous and ethanolic extracts of saffron $(\mathrm{P}<0.05)$.

\section{TABLE I}

The effect of aqueous extract $(200 \mathrm{mg} / \mathrm{kg})$ and ethanolic extract $(200 \mathrm{mg} / \mathrm{kg})$ of Crocus sativus on the lumbar spinal cord levels of MDA and GSH levels in 7 days CCI rats.

\begin{tabular}{l|c|c|c|c}
\hline & $\begin{array}{c}\text { Sham } \\
\text { group }\end{array}$ & $\begin{array}{c}\text { Control } \\
\text { group } \\
\text { (CCI rats } \\
\text { with NS) }\end{array}$ & $\begin{array}{c}\text { CCI- } \\
\text { Ethanolic } \\
\text { extract }\end{array}$ & $\begin{array}{c}\text { CCI- } \\
\text { Aqueous } \\
\text { extract }\end{array}$ \\
\hline MDA $_{(\text {nmol/g protein) }}$ & $2.98 \pm$ & $10.72 \pm$ & $4.84 \pm$ & $4.99 \pm$ \\
GSH $_{(\text {nmol/g protein) }}$ & $63.14 \pm$ & $1.3 \# \#$ & $0.5^{* *}$ & $0.9^{*}$ \\
\hline
\end{tabular}

Administration of extracts was started from the day of surgery and continued for seven consecutive days. CCI caused a significant increase in the spinal cord MDA contents, which was accompanied by a significant decrease in GSH level in comparison to sham operated animals. Data are presented as mean \pm SEM for $n=3$ /group. One-way ANOVA followed by Tukey's post-hoc test was used for multiple comparisons. $* \mathrm{P}<0.05$ and $* * \mathrm{P}<0.01$ indicate a statistically significant difference when compared to CCI-NS treated rats; \# $\mathrm{P}<0.05$, \#\# $\mathrm{P}<0.01$ : Difference between CCI-NS and sham group.

\section{THE EFFECTS OF Crocus sativus EXTRACTS ON THE BAX AND} BCL2 PROTEIN LEVELS

To analyze the amount of the Bax, Bcl-2 and betaactin, a relative protein ratio to sham animals was used. The results of western blotting analysis indicated that lumbar spinal cord levels of proapoptotic protein, Bax, increased within 3 days following sciatic nerve CCI, in comparison to the sham group $(\mathrm{P}<0.01)$. A slight and not significant change was observed in the anti-apoptotic protein Bcl-2 (Fig. 2A). As shown in Fig. 2B, a significant raise was observed in the $\mathrm{Bax} / \mathrm{Bcl} 2$ ratio of the $\mathrm{CCI}$ animals on day 3 post-CCI. CCI animals treated with $200 \mathrm{mg} / \mathrm{kg}$ of both ethanolic and aqueous extracts of saffron, for 7 days, showed a significant decrease in the Bax level on the day 3 post CCI, with a slight but not significant increase in the antiapoptotic protein $\mathrm{Bcl}-2$, resulting in a significant reduction in the $\mathrm{Bax} / \mathrm{Bcl} 2$ ratio in comparison to the control group $(\mathrm{P}<0.01$ and $\mathrm{P}<0.05$, respectively). The levels of Bax protein decreased in the spinal cord of CCI-NS animals on day 7 after CCI, whereas the Bcl2 increased; consequently, no significant differences were observed in the Bax/ Bcl2 ratio among control, sham group and animals treated with the extracts (data not shown).

\section{DISCUSSION}

Through our previous study, antiallodynia and antihyperalgesia effects of ethanolic and aqueous extracts of C. sativus (200 mg/kg, i.p.) for seven days were demonstrated in sciatic nerve chronic constriction injury of rats. In that study, threshold of pain in sham-operated animals was very similar to that observed in naive group (Amin and Hosseinzadeh 2012) which is consistent with many studies (Decostered and Woolf 2000, Urban et al. 2013).

Today many investigations have focused on the role of neuroinflammation in the pathogenesis of neuropathic pain which could contribute to cell death (Kawasaki et al. 2008, Jancalek et al. 2010). Agents that suppress inflammatory cytokine elevation including TNF- $\alpha$, IL-I $\beta$ and IL-6, have been advocated to be useful for the treatment of neuropathic pain (Kandhare et al. 2012). Therefore, in the present study, we evaluated potential antiapoptotic, anti-inflammatory and antioxidative effects of C. sativus in the lumbar spinal cord of 
A

A

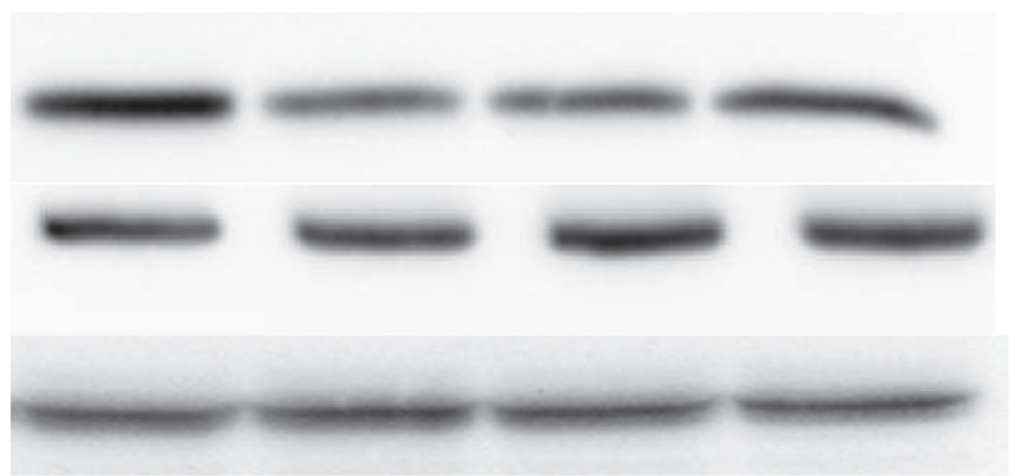

$\operatorname{Bax}(21 \mathrm{kDa})$

$\mathrm{Bc} / 2(26 \mathrm{kDa})$

Beta- Actin (42 kDa)

B

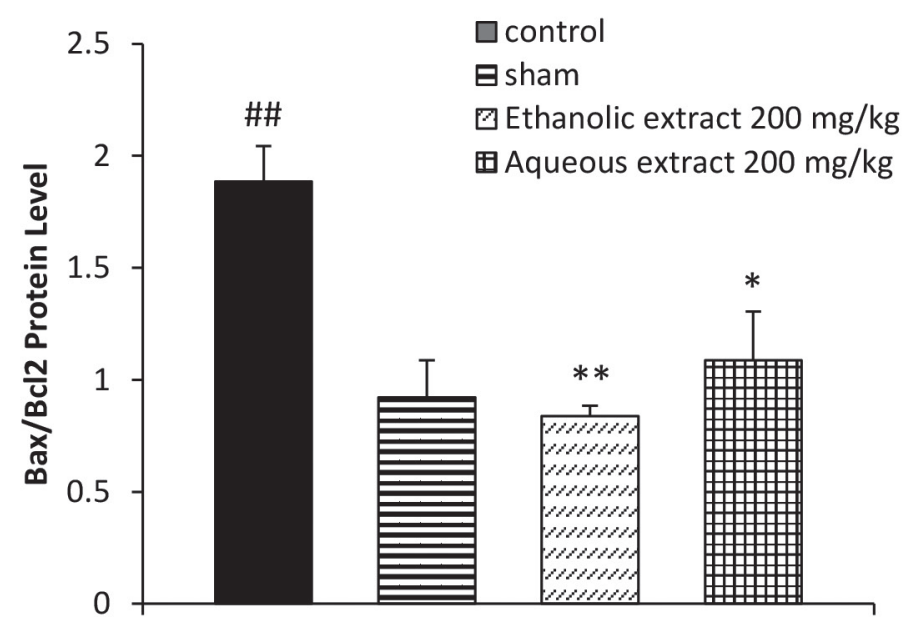

Figure 2 - The effect of aqueous extract (200 mg/kg) and ethanolic extract (200 mg/kg) of Crocus sativus on the spinal cord protein levels of Bax $(21 \mathrm{kDa})$ and $\mathrm{Bcl} 2(26 \mathrm{kDa})$ following western blotting (A) and relative density of Bax/ Bcl2 (B), 3 days after CCI. Administration of extracts was started from the day of surgery and continued for seven consecutive days. The semiquantitative analysis of protein levels was carried out by the "Gel Doc 2000 UV System" (Alliance 4.7). (1): CCI/NS (control); (2): Sham/ saline; (3): CCI /Ethanolic extract (200 mg/kg); (4): CCI/Aqueous extract $(200 \mathrm{mg} / \mathrm{kg})$. $\beta$-Actin is the loading protein control. Data were mean $\pm \mathrm{SEM}$ ( $\mathrm{n}=3$ /group). One-way ANOVA followed by Tukey's post-hoc test was used for multiple comparisons. ${ }^{*} \mathrm{p}<0.05 ;{ }^{*} \mathrm{P}<0.01$ : a statistically significant difference when compared to CCI saline-treated rats; \#\#P <0.01: Difference between CCI-NS and sham group.

CCI animals. CCI accompanied by a significant increase in the spinal cord levels of TNF- $\alpha$ and IL-1 $\beta$, which were more prominent on day 3 but remained high on day 7 post CCI. This result was consistent with the study of Kuang et al. 2012. However, IL-6 (with a delay) peaked on day 7 post CCI. A slow release of IL- 6 may be attributed to a more important role of this inflammatory cytokine in the maintenance phase of neuropathic pain or involvement of different mechanisms for producing proinflammatory cytokines. Induction of IL- 6 via TNF- $\alpha$ receptor 1 has been reported recently in a model of neuropathic pain (Lee et al. 2009). A week of daily administration of 200 $\mathrm{mg} / \mathrm{kg}$ aqueous and ethanolic extracts significantly attenuated the contents of IL-1 $1 \beta$, IL- 6 , and to a lesser extent, TNF- $\alpha$, in the spinal cord of animals subjected to nerve injury. 
The balance between Bax, a pro-apoptotic protein, and Bcl-2, an antiapoptotic protein, stabilizing membrane permeability is very important in apoptosis induction (Oltvai et al. 1993). Our western blot data showed that $\mathrm{Bax} / \mathrm{Bcl}-2$ ratio was elevated following CCI, supporting evidence that in the CCI of sciatic nerve, the development of neuropathic pain may be associated with the activation of apoptosis (Siniscalco et al. 2007, Maione et al. 2002). Bax/Bcl2 ratio declined in the spinal cord of rats treated with saffron's extracts on day 3 .

However, depending on the time point of study, there were differences in the pattern of apoptosis occurrence. Bcl2 was gradually elevated in CCI animals by day 7, as a result no significant difference was observed among groups. It seems that as a modulatory mechanism, apoptotic process, via mitochondria, is limited to the first few days after nerve injury. In agreement with this, an early apoptosis (2-3 days post-CCI), occurred transiently by the increased ratio of bax/bcl-2 gene in a study by de Novellis and co-workers (De Novellis et al. 2004). Authors in that study found an inversed pattern of bcl-2 family genes expression at later stages. Thus, there was a significant lowering in bax/bcl-2 and bcl-Xs/bcl-xL ratios over time as a consequence of increased expression of antiapoptotic bcl-2 and bcl-xL. The increased ratio between pro- and antiapoptotic gene bax/bcl-2 expression in the spinal cord of neuropathic rats was also limited to the first few days following nerve injury (Costa et al. 2006). However, it might be possible that apoptosis process will be activated again, after the time course of our study. Hence taking more stage samples, for example days 10 or 14 could help better characterize time course of apoptotic factors activation.

CCI- induced neuropathy was associated with the elevated levels of MDA and decreased levels of GSH in the spinal cord of 7 days CCI rats which is in line with previous studies, suggesting the contributory role of oxidative stress in neuropathic pain (Siniscalco et al. 2007). Seven days treatment of CCI animals with both ethanolic and aqueous extracts exhibited decreased the levels of MDA and restored the contents of GSH, as compared with vehicle treated control group.

Our results in this study confirm the complexity of underlying mechanisms in the neuropathic pain (Nickel et al. 2012). It seems that apoptosis is an early rapid event following the induction of injury, while contents of proinflammatory cytokines and oxidative stress markers contribute to both induction and maintenance of neuropathic pain.

Beneficial neuroprotective effects of ethanolic and aqueous extracts of saffron could be attributed to their active ingredients including polar carotenoids (crocins) that are glucosyl esters of crocetin (a polyene dicarboxylic acid), monoterpene aldehydes, like picocrocin (a glycosidic precursor of safranal) and safranal (Rezaee and Hosseinzadeh 2013, Alavizadeh and Hosseinzadeh 2013). Flavonoids such as rutin, quercetin and kaempferol, phenolic compounds such as gallic acid and pyrogallol, as well as other minor terpenoids, alkaloids and saponin contents are also present in stigma of saffron (Moraga et al. 2009, Hosseinzadeh and Younesi 2002, Karimi et al. 2010).

The antioxidant and anti-inflammatory activities of these compounds have been demonstrated in various studies (Karimi et al. 2010, Ishige et al. 2001). Although the comparison of the chemical constituents of aqueous and ethanolic of $C$. sativus was not determined in this study, based on our data as well as previous behavioral study (Amin and Hosseinzadeh 2012), it seems that no significant difference exists between the effects of the ethanolic extract to those of the aqueous extract. It is plausible that constituents of aqueous extract are more water hydrophilic/soluble ingredients such as crocins, with less permeability to CNS. While, ingredients of ethanolic extract are more oil soluble/hydrophobic including crocetin and safranal (Rezaee and Hosseinzadeh 2013), with more permeability to CNS. 
However, there is some evidence that crocins may be able to penetrate to the blood-brain barrier. Intraperitoneal administration of crocin to rats improved spatial memory deficit induced by chronic cerebral hypoperfusion (Hosseinzadeh et al. 2012). In another study, intraperitoneal injection of crocin enhanced functional recovery after sciatic nerve crush injury in rats (Tamaddonfard et al. 2013). In fact, based on our results, we cannot be sure about the central or peripheral and the real mechanisms of these combinations. However, involvement of both peripheral and central mechanisms is susceptible which is supported previous studies (Bridges et al. 2001).

In summary, data from current study suggest that ethanolic and aqueous extracts-mediated antinociceptive effects of saffron (stigma of C. sativus L.) could be at least in part through the modulation of oxidative stress, release of proinflammatory cytokines, as well as interfering with mitochondrial apoptosis pathways in CCI rats.

Although, further studies examining the exact constituents of this valuable plant and underlying mechanisms of saffron's antinociceptive effect are needed.

\section{ACKNOWLEDGMENTS}

We are thankful to the Pharmaceutical Research Center and the Vice Chancellor of Research, Mashhad University of Medical Sciences for financial support.

\section{RESUMO}

Em nosso estudo anterior, os extratos etanólico e aquoso de Crocus sativus provocaram efeitos antinociceptivos no modelo de lesão por constrição crônica $(\mathrm{CCI})$ da dor neuropática. Neste estudo, exploramos os efeitos anti-inflamatório, anti-oxidante e anti-apoptótico de tais extratos em animais CCI. Um total de 72 animais foi dividido em ratos CCI tratados com veículo, grupo de simulação, animais CCI tratados com a dose eficaz de extratos aquoso e etanólico (200 mg / kg, ip). Os níveis de citocinas pró-inflamatórias da medula espinhal lombar, incluindo o fator de necrose tumoral $\alpha(\mathrm{TNF}-\alpha)$, a interleucina-1 $\beta$ (IL-1 $\beta$ ) e a interleucina 6 (IL-6), foram avaliados nos dias 3 e 7 após a CCI $(n=3$, para cada grupo). As alterações de proteínas apoptóticas foram avaliadas nos dias 3 e 7 por western blotting. Marcadores de estresse oxidativo, incluindo malondialdeído (MDA) e glutationa reduzida (GSH), foram medidos no dia 7 após a CCI. Os níveis de citocinas inflamatórias aumentaram em animais CCI nos dias 3 e 7, o que foi suprimido por ambos os extratos. A proporção de Bax / Bcl2 estava elevada no dia 3, mas não no $7^{\circ}$ dia, nos animais CCI em comparação com os animais com operação simulada (sham), e diminuíram após o tratamento com ambos os extratos neste momento. Ambos os extratos atenuaram o MDA e aumentaram os níveis de GSH em animais CCI. Pode-se concluir que o açafrão alivia a dor neuropática, pelo menos em parte, por meio de atenuação de citocinas pró-inflamatórias, atividade antioxidante e vias apoptóticas.

Palavras-chave: Crocus sativus, lesão por constrição crônica, citocinas inflamatórias, estresse oxidativo, apoptose.

\section{REFERENCES}

ABDUllaev F. 1993. Biological effects of saffron. BioFactors 4: $83-86$

ABdullaev F AND EspinosA-AguirRe J. 2004. Biomedical properties of saffron and its potential use in cancer therapy and chemoprevention trials. Cancer Detect Prevent 28: 426-432.

ABE K AND SAITO H. 2000. Effects of saffron extract and its constituent crocin on learning behaviour and long-term potentiation. Phytother Res 14: 149-152.

AlavizadeH SH AND HosseinzadeH H. 2013. Bioactivity assessment and toxicity of crocin: A comprehensive review. Food Chem Toxicol 64: 65-80.

AMIN B AND HoSSEINZADEH H. 2012. Evaluation of aqueous and ethanolic extracts of saffron, Crocus sativus L., and its constituents, safranal and crocin in allodynia and hyperalgesia induced by chronic constriction injury model of neuropathic pain in rats. Fitoterapia 83: 888-895.

Assimopoulou A, Sinakos Z and Papageorgiou V. 2005 Radical scavenging activity of Crocus sativus L. extract and its bioactive constituents. Phytother Res 19: 997-1000.

BENNET GJ AND XIE YK. 1988. A peripheral mononeuropathy in rat that produces disorders of pain sensation like those seen in man. Pain 33: 87-107. 
BRADFORD MM. 1976. A rapid and sensitive method for the quantitation of microgram quantities of protein utilizing the principle of protein-dye binding. Anal Biochem 72: 248-254.

BRIDGES D, THOMPSON SW AND RICE AS. 2001. Mechanisms of neuropathic pain. Br J Anaesth 87: 12-26.

CHEESMAN KH. 1993. Lipid peroxidation in biological systems. In: HALLIWELL B AND ARUOMA OI (Eds), DNA and Free Radicals, London: Ellis Horwood, p. 12-17.

COOPER AJ AND KRISTAL BS. 1997. Multiple roles of glutathione in the central nervous system. Biol Chem 378: 793-802.

Costa B, Siniscalco D, Trovato AE, Comelli F, Sotgiu ML, Colleoni M, Maione S, Rossi F and Giagnoni G. 2006. AM404, an inhibitor of anandamide uptake, prevents pain behaviour and modulates cytokine and apoptotic pathways in a rat model of neuropathic pain. $\mathrm{Br}$ J Pharmacol 148: 1022-1032.

DeCOSTERED I AND WoOLF CJ. 2000. Spared nerve injury: an animal model of persistent peripheral neuropathic pain. Pain 87: 149-158.

De Novellis V, Siniscalco D, Galderisi U, Fuccio C, Nolano M, SAntoro L, Cascino A, Roth KA, Rossi F AND MAIONE S. 2004. Blockade of glutamate mGlu5 receptors in a rat model of neuropathic pain prevents early over-expression of pro-apoptotic genes and morphological changes in dorsal horn lamina II. Neuropharmacology 46 : 468-479.

Hariri AT, MoAllem SA, Mahmoudi M, Memar B AND HosSEINZADEH H. 2010. Subacute effects of diazinon on biochemical indices and specific biomarkers in rats: protective effects of crocin and safranal. Food Chem Toxicol 48: 2803-2808.

HosseinzadeH H, KARIMI G AND NiAPOOR M. 2003. Antidepressant effect of Crocus sativus L. stigma extracts and their constituents, crocin and safranal, in mice. ISHS Acta Horticulturae 650: 435-445.

HoSSEINZADEH H AND NASSIRI-ASL M. 2013. Avicenna's (Ibn Sina) the canon of medicine and saffron (Crocus sativus): a review. Phytother Res 27:475-483.

HosseinzadeH H AND Noraei NB. 2009. Anxiolytic and hypnotic effect of Crocus sativus aqueous extract and its constituents, crocin and safranal, in mice. Phytother Res 23: 768-774.

HosseinzadeH H AND SAdEGHNIA HR. 2005. Safranal, a constituent of Crocus sativus (saffron), attenuated cerebral ischemia induced oxidative damage in rat hippocampus. $\mathrm{J}$ Pharm Pharm Sci 8: 394-399.

Hosseinzadeh H, SAdeghnia HR, GHaeni FA, MOTAMEDSHARIATY VS AND MOHAJERI SA. 2012. Effects of saffron (Crocus sativus L.) and its active constituent, crocin, on recognition and spatial memory after chronic cerebral hypoperfusion in rats. Phytother Res 26: 381-386.

HosseinzadeH H, SADEghNIA HR AND RAHIMI A. 2008. Effect of safranal on extracellular hippocampal levels of glutamate and aspartate during kainic acid treatment in anesthetized rats. Planta Med 74: 1441-1445.
Hosseinzadeh H, Shamsaie F And Mehri S. 2009. Antioxidant activity of aqueous and ethanolic extracts of Crocus sativus L. stigma and its bioactive constituents, crocin and safranal. Pharmacogn Mag 5: 419-424.

HosseinZADEH H AND SHARIATY V. 2007. Anti-nociceptive effect of safranal, a constituent of Crocus sativus (saffron), in mice. Pharmacologyonline 2: 498-503.

HosseINZADEH H AND YounesI HM. 2002. Antinociceptive and anti-inflammatory effects of Crocus sativus L. stigma and petal extracts in mice. BMC Pharmacol 2: 7-12.

HOSSEINZADEH H AND ZIAEI T. 2006. Effects of Crocus sativus stigma extract and its constituents, crocin and safranal, on intact memory and scopolamine-induced learning deficits in rats performing the morris water maze task. J Med Plants 5: 40-50.

ISHIGE K, SCHUBERT D AND SAGARA Y. 2001. Flavonoids protect neuronal cells from oxidative stress by three distinct mechanisms. Free Radic Biol Med 30: 433-446.

JANCALEK R, DubOVy P, SVIZENSKA I AND KLUSAKova I. 2010. Bilateral changes of TNF alpha and IL-10 protein in the lumbar and cervical dorsal root ganglia following a unilateral chronic constriction injury of the sciatic nerve. $\mathrm{J}$ Neuroinflammation 7: 11.

Kandhare AD, Raygude KS, Ghosh P, Ghule AE AND BODHANKAR SL. 2012. Neuroprotective effect of naringin by modulation of endogenous biomarkers in streptozotocin induced painful diabetic neuropathy. Fitoterapia 83: 650-659.

Karimi E, OSKoueian E, Hendra R AND JaAFAR HZ. 2010. Evaluation of Crocus sativus L. stigma phenolic and flavonoid compounds and its antioxidant activity. Molecules 15: 6244-6256.

KAWASAKI Y, ZHANG L, CHENG JK AND Ji RR. 2008. Cytokine mechanisms of central sensitization: distinct and overlapping role of interleukin-1 $\beta$, interleukin- 6 , and tumor necrosis factor- $\alpha$ in regulating synaptic and neuronal activity in the superficial spinal cord. J Neurosci 28:5189-5194.

KuANG X, HuANG Y, GU HF, Zu XY, ZOU WY, SONG ZB AND GUO QL. 2012. Effects of intrathecal epigallocatechin gallate, an inhibitor of Toll-like receptor 4, on chronic neuropathic pain in rats. Eur J Pharmacol 676: 51-56.

LARI P, ABNOUS K, IMENSHAHIDI M, RASHEDINIA M, RAZAVI M AND HOSSEINZADEH H. IN PRESS. Evaluation of diazinoninduced hepatotoxicity and protective effects of crocin. Toxicol Ind Health.

LEE KM, JEON SM AND CHO HJ. 2009. Tumor necrosis factor receptor 1 induces interleukin-6 upregulation through NFkappaB in a rat neuropathic pain model. Eur J Pain 13: 794-806.

Maione S, Siniscalco D, Galderisi U, De Novellis V, Uliano R, Di Bernardo G, Berrino L, Cascino A AND Rossi F. 2002. Apoptotic genes expression in the lumbar dorsal horn in a model of neuropathic pain in rat. Neuroreport 13: 101-106.

MeHdizAdeH R, PARIZADEH MR, KHOOEI AR, MEHRI S AND HOSSEINZADEH H. 2013. Cardioprotective effect of saffron extract and safranal in isoproterenol-induced myocardial infarction in wistar rats. Iran J Basic Med Sci 16: 56-63. 
Mehri S, ABnous K, Mousavi SH, Shariaty VM AND HoSSEINZADEH H. 2012. Neuroprotective effect of crocin on acrylamide-induced cytotoxicity in PC12 cells. Cell Mol Neurobiol 32: 227-235.

Moraga AR, Rambla JL, Ahrazem O, Granell A AND GOMEZ-GOMEZ L. 2009. Metabolite and target transcript analyses during Crocus sativus stigma development. Phytochemistry 70: 1009-1016.

Moron MS, DepierRe JW AND MANNERVIK B. 1979. Levels of glutathione, glutathione reductase and glutathione S-transferase activities in rat lung and liver. Biochim Biophys Acta 582: 67-78.

NAM KN ET AL. 2010. Anti-inflammatory effects of crocin and crocetin in rat brain microglial cells. Eur J Pharmacol 648: $110-116$.

Nickel FT, SeIFERT F, LANZ S AND MAIHOFNER C. 2012 Mechanisms of neuropathic pain. Eur Neuropsychopharmacol 22: 81-91.

Oltvai ZN, Milliman CL AND KoRSMeyer SJ. 1993. Bcl-2 heterodimerizes in vivo with a conserved homolog, Bax, that accelerates programmed cell death. Cell 74: 609-619.

Rastgoo M, Hosseinzadeh H, Alavizadeh H, AbBasi A, AYATI Z AND JAAFARI MR. 2013. Antitumor activity of PEGylated nanoliposomes containing crocin in mice bearing C26 colon carcinoma. Planta Med 79: 447-451.

REECE TB, OKONKWo DO, Ellman PI, WARREN PS, SMith RL, HaWkins AS, Linden J, KRon IL, Tribble CG AND KERN JA. 2004. The evolution of ischemic spinal cord injury in function, cytoarchitecture, and inflammation and the effects of adenosine A2A receptor activation. J Thorac Cardiovasc Surg 128: 925-932.
REZAeE R AND HosseinZAdeH H. 2013. Safranal: from an aromatic natural product to a rewarding pharmacological agent. Iran J Basic Med Sci 16: 12-26.

Siniscalco D, Fuccio C, Giordano C, Ferraraccio F, Palazzo E, LuONGo L, Rossi F, Roth KA, MAIONE S AND DE Novellis V. 2007. Role of reactive oxygen species and spinal cord apoptotic genes in the development of neuropathic pain. Pharmacol Res 55: 158-166.

TAMADDONFARD E, FARSHID AA, AHMADIAN E AND HAMIDHOSEYNI A. 2013. Crocin enhanced functional recovery after sciatic nerve crush injury in rats. Iran $\mathrm{J}$ Basic Med Sci 16: 83-90.

UCHIYAMA M AND MiHARA M. 1978. Determination of malonaldehyde precursor in tissues by thiobarbituric acid test. Anal Biochem 86: 271-278.

Urban R, Scherrer G, Goulding EH, TECOTT LH AND BASBAU AI. 2011. Behavioral indices of ongoing pain are largely unchanged in male mice with tissue or nerve injury-induced mechanical hypersensitivity. Pain 152: 990-1000.

ZIMMERMAN N. 1983. Ethical guidelines for investigation of experimental pain in conscious animals. Pain 16: 109-110. 